\title{
CD47 suppresses phagocytosis by repositioning SIRPA and preventing integrin activation
}

\author{
Meghan A. Morrissey ${ }^{1,2}$ and Ronald D. Vale ${ }^{1,2 *}$. \\ ${ }^{1}$ Department of Cellular and Molecular Pharmacology, University of California San \\ Francisco, San Francisco, CA 94158 \\ ${ }^{2}$ Howard Hughes Medical Institute, University of California San Francisco, San \\ Francisco, CA 94158
}

${ }^{*}$ Corresponding Author 


\section{Summary}

3 Macrophages must engulf dead cells, debris, and pathogens, while selecting against 4 healthy cells to prevent autoimmunity. Healthy cells express CD47 on their surface, 5 which activates the SIRPA receptor on macrophages to suppress engulfment. Cancer

6 cells overexpress CD47 to evade clearance by the innate immune system, making the 7 CD47-SIRPA signaling axis an appealing therapeutic target. However, the mechanism 8 by which CD47-SIRPA inhibits engulfment remains poorly understood. Here, we dissect 9 SIRPA signaling using a reconstituted target with varying concentrations of activating 10 and inhibitor ligands. We find that SIRPA is excluded from the phagocytic synapse 11 between the macrophage and its target unless CD47 is present. Artificially directing 12 SIRPA to the kinase-rich synapse in the absence of CD47 activates SIRPA and 13 suppresses engulfment, indicating that the localization of the receptor is critical for 14 inhibitory signaling. CD47-SIRPA inhibits integrin activation in the macrophage, 15 reducing macrophage-target contact and suppressing phagocytosis. Chemical

16 activation of integrins can override this effect and drive engulfment of CD47-positive

17 targets, including cancer cells. These results suggest new strategies for overcoming 18 CD47-SIRPA inhibition of phagocytosis with potential applications in cancer 19 immunotherapy. 


\section{Introduction}

22 The innate immune system is finely balanced to rapidly activate in response to

23 pathogenic stimuli, but remain quiescent in healthy tissue. Macrophages, key effectors

24 of the innate immune system, measure activating and inhibitory signals to set a

25 threshold for engulfment and cytokine secretion. The cell surface protein CD47 is a

26 "Don't Eat Me" signal that protects healthy cells from macrophage engulfment and is

27 often upregulated by cancer cells to evade innate immune detection (Chao et al., 2012;

28 Jaiswal et al., 2009; Majeti et al., 2009; Oldenborg et al., 2001, 2000). CD47 function-

29 blocking antibodies result in decreased cancer growth or tumor elimination (Advani et

30 al., 2018; Chao et al., 2010a; Gholamin et al., 2017; Jaiswal et al., 2009; Willingham et

31 al., 2012). Despite the therapeutic promise of manipulating CD47 signaling, the

32 mechanism by which CD47 suppresses macrophage signaling is unclear.

CD47 on the surface of cancer cells binds to SIRPA in macrophages or dendritic cells to 35 prevent activation (Jiang et al., 1999; Liu et al., 2015; Okazawa et al., 2005; Seiffert et al., 1999; Tseng et al., 2013; Yi et al., 2015). Activation of the inhibitory receptor SIRPA must be controlled with high fidelity to suppress engulfment of viable cells when CD47 is present while allowing for robust engulfment of targets lacking CD47. CD47 binding triggers SIRPA phosphorylation by Src family kinases (Barclay and Brown, 2006), but how CD47 binding is translated across the cell membrane to drive SIRPA

41 phosphorylation is not known. Activated SIRPA recruits the phosphatases SHP-1 and

42 SHP-2 (Fujioka et al., 1996; Noguchi et al., 1996; Okazawa et al., 2005; Oldenborg et

43 al., 2001; Veillette et al., 1998). The downstream events that shut off the engulfment

44 program are not clear.

In vivo, CD47 has been reported to suppress multiple different pro-engulfment "Eat Me"

47 signals, including IgG, complement and calreticulin (Chen et al., 2017; Gardai et al., 48 2005; Oldenborg et al., 2001). This complexity, in addition to substantial variation in 49 target size, shape and concentration of "Eat Me" signals, can make a quantitative, 50 biochemical understanding of receptor activation difficult. To overcome this problem, we 
51 utilize a synthetic target cell-mimic with a defined complement of signals to interrogate 52 the mechanism of SIRPA activation and its downstream targets. We find that CD47 53 ligation alters SIRPA localization, positioning SIRPA for activation at the phagocytic 54 synapse. At the phagocytic synapse, SIRPA inhibits integrin activation to limit 55 macrophage spreading across the surface of the engulfment target. Directly activating 56 integrin eliminated the effect of CD47 and rescued engulfment. Activation of integrin

57 also allowed macrophages to engulf cancer cells, similar to the effect observed with a 58 CD47 function-blocking antibody. 


\section{Results}

\section{CD47-SIRPA signaling suppresses IgG and phosphatidylserine "Eat Me" signals}

To study the mechanism of "Eat Me" and "Don't Eat Me" signal integration during engulfment, we used a reconstituted engulfment target (Figure 1A). Silica beads were coated in a supported lipid bilayer to mimic the surface of a cancer cell. To activate engulfment, we introduced IgG, a well-defined "Eat Me" signal that synergizes with CD47 blockade to promote cancer cell clearance (Chao et al., 2010a; Freeman and Grinstein, 2014). IgG is recognized by the Fc y Receptor family (FcR), which activates downstream signaling and engulfment (Freeman and Grinstein, 2014). To activate SIRPA, we incorporated the CD47 extracellular domain at a surface density selected to mimic the CD47 density on cancer cells ( 600 molecules $/ \mu m^{2}$, Figure $\left.S 1\right)$.

Using this system, we tested the effect of CD47 on engulfment across a titration of $\lg \mathrm{G}$

74 densities (Figure S1). We mixed beads with the macrophage-like cell line RAW264.7 and measured the number of internalized beads by confocal microscopy. We found that CD47-SIRPA signaling suppressed engulfment at intermediate IgG densities, but did not appreciably affect engulfment of targets with high densities of bound IgG (Figure 1BD). This suppression was dependent on CD47 binding as a mutated CD47 extracellular domain (F37D, T115K) that is unable to bind to SIRPA (Hatherley et al., 2008) was also unable to suppress engulfment.

82 We further examined whether CD47-SIRPA signaling could suppress engulfment of

83 targets mimicking apoptotic corpses. A critical "Eat Me" signal from apoptotic corpses is

84 phosphatidylserine, which becomes exposed on the outer leaflet of the plasma

85 membrane during cell stress, apoptosis (Fadok et al., 1992; Poon et al., 2014), and on

86 some cancer cells (Birge et al., 2016; Utsugi et al., 1991). We found that engulfment of

87 beads containing $10 \%$ phosphatidylserine in the supported lipid bilayer was inhibited by

88 the inclusion of CD47 on the bilayer (Figure 1E, Figure S1). Together, these data show

89 that CD47-SIRPA signaling can block engulfment driven by $\lg G$ and phosphatidylserine. 
90 Thus, bilayer-coated beads provide a well-defined and tunable platform for studying the

91 integration of "Eat Me" and "Don't Eat Me" signals during engulfment.

93 CD47 ligation relocalizes SIRPA to the phagocytic synapse

95 We next sought to determine the mechanism by which CD47 ligation regulates SIRPA

96 activity. We first examined SIRPA localization during phagocytosis of IgG-coated beads.

97 In the absence of CD47, SIRPA was segregated away from the phagocytic cup that 98 enveloped IgG-coated beads (Figure 2A). Similarly, SIRPA was depleted at the center 99 of the immunological synapse between a macrophage and a supported lipid bilayer 100 containing phosphatidylserine (Figure S2). In contrast, in the presence of CD47, SIRPA 101 remained at the phagocytic cup (Figure 2A). These data demonstrate that CD47 recruits 102 SIRPA to the phagocytic synapse.

103

104 We next sought to address the mechanism of SIRPA segregation away from the 105 phagocytic cup in the presence of $\lg G$ and absence of CD47. We hypothesized that 106 exclusion of unligated SIRPA from the synapse could be driven by its heavily 107 glycosylated extracellular domain, either by interactions with the surrounding glycocalyx 108 or steric exclusion from the spatially restricted phagocytic synapse. We therefore 109 created a SIRPA chimeric receptor where the extracellular domain was replaced with a 110 small, inert protein domain (FRB ${ }^{\text {ext }}$-SIRPA; Figure $2 B$ ). Unlike full length SIRPA, FRB ${ }^{\text {ext }}$ 111 SIRPA was not segregated away from the cell-target synapse (Figure 2C, D). This 112 result demonstrates that the extracellular domain of SIRPA is required for SIRPA 113 exclusion from the phagocytic cup.

\section{Targeting SIRPA to the phagocytic synapse suppresses engulfment}

117 Receptor activation by Src family kinases at the phagocytic cup is favored due to 118 exclusion of bulky phosphatases like CD45 (Freeman et al., 2016; Goodridge et al., 119 2011). We therefore hypothesized that positioning SIRPA at the phagocytic cup may 120 drive receptor activation. To distinguish between the effects of CD47 binding and 
121 synapse localization, we developed a chimeric SIRPA receptor that localized to the 122 phagocytic synapse in the absence of CD47. We replaced the SIRPA extracellular 123 domain with the IgG-binding extracellular domain of the FcyRI $\alpha$ chain (Figure 2B; 124 termed $\mathrm{FcR} 1^{\text {ext }}$-SIRPA $\left.{ }^{\text {int }}\right)$. This receptor is driven into the synapse by $\lg$ binding 125 instead of CD47 (Figure 2C, D). Expression of this synapse-localized chimera 126 suppressed engulfment of IgG-coated beads in the absence of CD47 (Figure 2E, Figure 127 S2). Thus, targeting SIRPA to the phagocytic cup is sufficient to inhibit engulfment, even 128 in the absence of its natural ligand CD47.

130 As an alternative strategy to control the localization of SIRPA activity, we used a 131 chemically inducible dimerization system (Spencer et al., 1993). We fused one half of

132 the chemically inducible dimer to FcR (FcR $\gamma$ chain-FKBP) and the second to a soluble 133 SIRPA intracellular domain (FRB-SIRPA ${ }^{\text {int }}$, Figure 2F). In the presence of the small 134 molecule rapamycin, FKBP and FRB form a high-affinity dimer (Spencer et al., 1993), 135 thereby recruiting the SIRPA intracellular domain to FcR. In the absence of rapamycin, 136 cells efficiently engulfed IgG-coated beads (Figure 2F, Figure S2). In contrast, 137 rapamycin-induced recruitment of the SIRPA intracellular domain to the FcR $\gamma$ chain 138 significantly suppressed engulfment (Figure 2F).

140 We next examined the extracellular domain truncation of SIRPA (FRB ${ }^{\text {ext }}$-SIRPA) that 141 was not excluded from the phagocytic synapse (Figure 2B). FRB ${ }^{\text {ext }}$-SIRPA constitutively 142 suppressed engulfment (Figure 2G), demonstrating that exclusion of SIRPA is essential 143 for efficient engulfment. Taken together, these experiments show that CD47 activates 144 SIRPA by recruiting it to the phagocytic synapse.

\section{FcR phosphorylation is not a major target of CD47-SIRPA signaling}

148 We next sought to determine how activated SIRPA inhibits engulfment. Phosphorylated 149 SIRPA recruits the phosphatases SHP-1 and SHP-2 via their phosphobinding SH2 150 domains but the downstream targets of SHP-1 and SHP-2 are not known (Fujioka et al., 151 1996; Noguchi et al., 1996; Okazawa et al., 2005; Oldenborg et al., 2001; Veillette et al., 
152 1998). One potential target of SIRPA-bound SHP phosphatases is FcR itself. When 153 encountering an IgG-bound bilayer, macrophages clustered IgG into mobile

154 microclusters (Figure 3, Movie S1) that recruited Syk (Figures S3 (Lin et al., 2016).

155 When CD47 was present, these microclusters still formed and recruited Syk, suggesting 156 that FcR is still phosphorylated (Figures $3 A$ and S3, Movie S2). Further, when we 157 looked at SIRPA localization at the cell-target interface at high resolution, we found that, 158 even in the presence of CD47, SIRPA did not co-localize with FcR clusters, suggesting 159 that SIRPA is not positioned to dampen receptor activation (Figure S3). Overall, this 160 suggests that changes to FcR activation and Syk recruitment are unlikely to account for 161 the effect of SIRPA, consistent with previous biochemical observations (Okazawa et al., 162 2005; Tsai and Discher, 2008).

CD47 prevents integrin activation

166 During our TIRF experiments, we observed a difference in the spreading of cells on 167 bilayers containing IgG alone versus IgG plus CD47. On IgG-coated bilayers, cells 168 rapidly spread across the bilayer surface (Figure 3A, Movie S1). In contrast, 169 macrophages encountering an IgG and CD47-containing bilayer exhibited reduced cell 170 spreading (Figure $3 \mathrm{~A}$ and $3 \mathrm{~B}$, Movie S2). These data shows that CD47 inhibits cell 171 spreading across a target substrate.

173 Cell spreading is thought to involve activation of integrins and the actin cytoskeleton 174 (Springer and Dustin, 2011). Inactive integrins exist in a low affinity, bent confirmation 175 (Springer and Dustin, 2011). Upon activation, the extracellular domain extends into an 176 open conformation that can bind many ligands with high affinity (Freeman and Grinstein, 177 2014; Springer and Dustin, 2011). FcR activation stimulates inside-out activation of 178 integrins (Dupuy and Caron, 2008; Jones et al., 1998). Activated integrins can then 179 promote engulfment, either by increasing adhesion to the target particle or by 180 reorganizing the actin cytoskeleton (Dupuy and Caron, 2008; Wong et al., 2016). We 181 found that inhibiting integrin with a $\beta 2$ integrin function-blocking antibody (2E6) or Fab 
182 dramatically decreased engulfment efficiency (Figure 3C and S3), demonstrating that

183 inactivating integrins is sufficient to suppress engulfment.

185 Because integrin is required for cell spreading and engulfment (Springer and Dustin, 186 2011), we hypothesized that CD47-SIRPA signaling may inhibit engulfment by

187 preventing inside-out activation of integrin. Supporting this hypothesis, a previous study 188 identified phosphopaxillin, which is specifically recruited to sites of integrin activation, as 189 one of a number of phosphoproteins affected by CD47 (Geiger et al., 2009; Tsai and 190 Discher, 2008). We found that the enrichment of phospho-paxillin at the interface of the 191 macrophage with an IgG-coated bead was substantially diminished by the simultaneous 192 presence of CD47 on the bead (Figure 3D). Together, these data indicate that CD47193 SIRPA signaling prevents integrin activation.

\section{Activating integrin bypasses CD47-SIRPA inhibitory signaling}

CD47-SIRPA has previously been reported to affect paxillin and myosin 198 phosphorylation, as well as F-actin recruitment (Tsai and Discher, 2008). It is not clear 199 which of these is a target of CD47 signaling and which is a secondary effect of altered 200 upstream signaling (Tsai and Discher, 2008). We hypothesized that if SIRPA signaling 201 suppresses engulfment primarily by inhibiting integrin inside-out activation, then directly 202 activating integrin might bypass SIRPA-mediated inhibition and permit bead engulfment 203 (Figure 4A). Alternatively, if the target of CD47-SIRPA signaling is in a parallel pathway 204 or downstream of integrin activation, then activating integrin should not rescue 205 engulfment following SIRPA activation. To activate integrin, we treated macrophages 206 with manganese, which locks integrin into a high-affinity open conformation (Dransfield 207 et al., 1992). We found that macrophages treated with $1 \mathrm{mM}$ manganese engulfed 208 beads with a similar efficiency whether or not CD47 was conjugated to the supported 209 lipid bilayer (Figure 4B). Importantly, manganese did not trigger bead engulfment on its 210 own or dramatically enhance engulfment of IgG-coated beads in the absence of CD47 211 (Figure 4B,C), establishing that increasing integrin activation is not sufficient to trigger 
212 engulfment. Thus, a manganese-induced increase in engulfment was specific to beads

213 coated with CD47 and IgG.

215 As an alternative strategy to activate integrins, we incubated macrophages with beads 216 containing a surplus of high affinity integrin ligand, ICAM-1 (Springer and Dustin, 2011).

217 ICAM-1 was sufficient to activate integrin and recruit phophopaxillin even in the 218 presence of CD47 (Figure 4D). Inclusion of high concentrations of ICAM-1 abrogated 219 the inhibitory effect of CD47 on phagocytosis, but did not dramatically alter the 220 engulfment efficiency of IgG coated beads in the absence of CD47 (Figure 4E).

222 CD47 has previously been reported to inhibit downstream steps in the phagocytic 223 signaling pathway, including actin accumulation at the phagocytic cup (Tsai and 224 Discher, 2008). Despite the presence of CD47, ICAM-1-bound beads had similar levels 225 of actin accumulation as beads lacking CD47 (Figure 4F). This demonstrates that 226 activating integrins reactivates downstream signaling in the presence of CD47.

227 Together, these data suggest that inside-out activation of integrin is the primary target of 228 CD47-SIRPA signaling.

Integrin activation drives cancer cell engulfment

232 Many cancer cells overexpress CD47 to evade the innate immune system despite 233 increased expression of "Eat Me" signals such as calreticulin or phosphatidylserine 234 (Birge et al., 2016; Chao et al., 2010b; Gardai et al., 2005; Utsugi et al., 1991). Blocking 235 CD47 with a therapeutic antibody allows "Eat Me" signals to dominate, resulting in 236 engulfment of whole cancer cells (Jaiswal et al., 2009; Majeti et al., 2009). We 237 hypothesized that exogenous activation of integrin would bypass the CD47 signal on the 238 surface of cancer cells, allowing for engulfment. To test this, we incubated bone marrow 239 derived mouse macrophages with a CD47-positive murine leukemia line, L1210 (Chen 240 et al., 2017). We found that activating integrins with $100 \mu \mathrm{M}$ manganese increased the 241 ability of macrophages to engulf cancer cells, reaching a similar efficiency as treatment 242 with a CD47 function-blocking antibody (Figure 4G,H; Movie S3). Manganese did not 
bioRxiv preprint doi: https://doi.org/10.1101/752311; this version posted August 30, 2019. The copyright holder for this preprint (which was not certified by peer review) is the author/funder, who has granted bioRxiv a license to display the preprint in perpetuity. It is made available under aCC-BY-NC-ND 4.0 International license.

243 directly affect cancer cell viability over the time course of this experiment (Figure S4). 244 This data shows that activating integrins bypasses the suppressive CD47 signal on the 245 surface of cancer cells. 


\section{Discussion}

248 CD47-SIRPA signaling suppresses engulfment, protecting viable cells and allowing 249 cancer cells to evade the innate immune system (Jaiswal et al., 2009; Majeti et al., 250 2009; Oldenborg et al., 2000). Although CD47 blockade is a promising new target for 251 cancer therapies (Advani et al., 2018; Gholamin et al., 2017; Willingham et al., 2012), 252 the mechanism of CD47-SIRPA signaling has not been clarified. We demonstrate that 253 localizing SIRPA to the phagocytic synapse is sufficient to activate this inhibitory 254 receptor. Once active, SIRPA suppresses engulfment by preventing integrin activation 255 (Figure 4I).

Our results demonstrate that SIRPA localization is a key determinant of its activity. In 258 the absence of CD47, SIRPA is relegated to the phosphatase-rich zone outside the cell 259 bead interface (Freeman et al., 2016; Goodridge et al., 2011). This localization prevents 260 SIRPA activation. Conversely, CD47 binding retains SIRPA at the Src-kinase rich 261 phagocytic cup, where it is activated and suppresses engulfment. Spatial segregation of 262 Src-family kinase activity at the central phagocytic synapse and CD45 phosphatase 263 activity at the periphery underlies the activation of many activating receptors (TCR, FC 264 Receptor, (Freeman et al., 2016; James and Vale, 2012). Our work expands this model, 265 suggesting that exclusion of inhibitory receptors like SIRPA may be a pre-requisite for 266 efficient engulfment. Further, these data suggest a new paradigm for regulating 267 inhibitory receptors based on conditional recruitment to the immunological synapse.

SIRPA exclusion from the phagocytic synapse in the absence of CD47 prevents basal

270 inhibition of engulfment and allows positive signaling to dominate. This exclusion 271 requires the extracellular domain of SIRPA, as replacing the extracellular domain with a 272 small, inert protein (FRB) allowed SIRPA to enter the phagocytic synapse (Figure 2). 273 CD45, the transmembrane phosphatase that negatively regulates Fc Receptor 274 activation, is sterically excluded from the synapse between a $\mathrm{T}$ cell or macrophage and 275 its target (Freeman et al., 2016; Goodridge et al., 2011; James and Vale, 2012). The 276 SIRPA extracellular domain is predicted to be smaller than CD45 (aglycosylated 
277 proteins are $12 \mathrm{~nm}$ and $17 \mathrm{~nm}$ respectively (Chang et al., 2016; Hatherley et al., 2008).

278 Biophysical studies have shown that proteins that are the same size or slightly smaller

279 than the height of a cell-cell synapse are excluded from the synapse due to steric 280 constraints (Schmid et al., 2016). Ligand binding is sufficient to drive synapse 281 localization (Schmid et al., 2016). Thus SIRPA may be sterically excluded unless CD47

282 ligation overcomes the energetic barrier preventing SIRPA from entering the 283 immunological synapse. Alternatively, other mechanisms, such as lateral crowding or 284 interactions with the surrounding glycocalyx, could drive SIRPA exclusion from the 285 synapse.

287 After addressing the mechanism of SIRPA activation, we sought to identify the targets 288 of CD47-SIRPA signaling. Previous work has shown that SIRPA activation dramatically 289 reduces global phosphotyrosine, including phosphorylation of mDia, paxillin, talin, 290 alpha-actinin and non-muscle myosin IIA (Okazawa et al., 2005; Tsai and Discher, 291 2008). However, discerning between direct targets of SIRPA-bound phosphatases and 292 indirect targets resulting from an upstream block in the engulfment signaling cascade 293 has been challenging. Because blocking non-muscle myosin II decreases phagocytosis 294 to a similar extent as CD47, myosin has been presumed to be the primary target of 295 SIRPA (Chao et al., 2012; Tsai and Discher, 2008). However, we demonstrate that the 296 inhibitory effect of CD47-SIRPA can be eliminated by re-activating integrin, suggesting 297 that the direct targets of SIRPA-bound SHP phosphatases are upstream of integrin 298 activation. SHP-2 has previously been shown to directly dephosphorylate Fak (Yu et al., 299 1998) and vinculin (Campbell et al., 2018), thus SHP-2 may act upon these key integrin 300 regulators. However, given the broad specificity of SHP-1 and SHP-2, these 301 phosphatases may dephosphorylate several targets at the phagocytic cup to suppress 302 signaling.

304 Our work provides new insights into the connection between SIRPA and integrins. While 305 phosphopaxillin (Tsai and Discher, 2008), has previously been shown to be affected by 306 CD47-SIRPA, the relative importance of integrin signaling had not previously been 307 addressed. We show that CD47-SIRPA prevents integrin activation, allowing 
308 macrophages to quickly discriminate between targets based on the presence of CD47.

309 SIRPA overexpression has previously been shown to decrease surface levels of integrin

310 over time (Liu et al., 2008). While this decrease in integrin expression does not explain

311 how SIRPA immediately prevents phagocytosis of a CD47-bound target, it suggests that

312 long term exposure to activated SIRPA may decrease overall phagocytic capacity, even

313 of targets lacking CD47. In addition, SIRPA has been implicated in regulating cell

314 motility, as fibroblasts lacking SIRPA have impaired motility (Alenghat et al., 2012;

315 Inagaki et al., 2000; Motegi et al., 2003). In this case, un-ligated SIRPA may instead act

316 downstream of integrin, as eliminating SIRPA decreases integrin responsiveness

317 (Alenghat et al., 2012; Inagaki et al., 2000).

319 By suppressing integrin activation, CD47-SIRPA signaling may be able to suppress 320 many different signaling pathways. Interestingly, CD47 has been reported to affect 321 dendritic cell activation, cancer cell killing via a nibbling behavior (called trogocytosis), 322 and complement-mediated engulfment (Caron et al., 2000; Matlung et al., 2018;

323 Oldenborg et al., 2001; Tamada et al., 2004; Wu et al., 2018; Yi et al., 2015). These 324 processes are triggered by diverse positive signaling receptors, but all require inside-out 325 activation of integrin (Caron et al., 2000; Matlung et al., 2018; Oldenborg et al., 2001; 326 Tamada et al., 2004; Wu et al., 2018; Yi et al., 2015). Targeting integrin, a common co327 receptor, may explain how CD47-SIRPA signaling can regulate these diverse 328 processes.

330 Finally, we found that integrin activation by manganese can drive engulfment of whole 331 cancer cells by bone marrow derived macrophages. As a cancer treatment, CD47 332 blockade synergizes with therapeutic antibodies, like rituximab (Advani et al., 2018; 333 Chao et al., 2010a). Activating integrins with a small molecule agonist in combination 334 with antibody therapeutics may have a similar synergistic effect as CD47 blockade. 335 Small molecule agonists of CD11b, an integrin subunit highly expressed in 336 macrophages, drive tumor regression in a macrophage-dependent manner (Panni et al., 337 2019; Schmid et al., 2018). Our data suggests that these small molecules may allow 338 macrophages to bypass the CD47 inhibitory signal. 


\section{Acknowledgments}

341 We thank K. McKinley and O. Klein for providing mouse long bones as a source for

342 hematopoietic stem cells. We thank members of the Vale lab for critical feedback on this

343 manuscript. M.A.M. was supported by the National Institute of General Medical

344 Sciences of the National Institutes of Health under award number F32GM120990. This

345 work was funded by the Howard Hughes Medical Institute.

\section{Competing Financial Interests}

348 The authors declare no competing financial interests. 


\section{$350 \quad$ Figure Legends}

Figure 1: CD47-SIRPA suppresses IgG and PS dependent engulfment

(A) Schematic shows the supported lipid bilayer system used in this study. Anti-biotin $\lg G$ is bound to biotinylated lipids. IgG is recognized by Fc Receptor in the macrophage. The extracellular domain of CD47-His 10 is bound to Ni-NTA-conjugated lipids and recognized by SIRPA in the macrophage. (B) Silica beads are coated in a supported lipid bilayer and incubated with the indicated concentration of IgG and either CD47 (red) or an inactive mutant CD47 (F37D, T115K; green). The functionalized beads were added to RAW264.7 macrophages and fixed after $30 \mathrm{~min}$. The average number of beads per macrophage was assessed by confocal microscopy and normalized to the maximum bead eating observed in that replicate. Each dot represents an independent replicate ( $n \geq 100$ cells analyzed per experiment), and the trendline connects the average of three replicates. (C) Still images depict the assay described in (B). The supported lipid bilayers contain the fluorescently-labeled lipid atto390-DOPE (green) and the macrophages membranes are labeled with CellMask (magenta). Internalized beads are indicated with a yellow dot. (D) Histograms depict the fraction of cells engulfing the indicated number of beads (pooled data from the three independent replicates shown in (B)). Macrophages encountering CD47conjugated beads (right) were less likely to engulf, and those that did engulfed fewer beads. CD47 ${ }^{\mathrm{F} 37 \mathrm{D}, \mathrm{T115K}}$, a mutant that cannot bind SIRPA, was used as a control. (E) Macrophages were incubated with beads coated in a supported lipid bilayer containing $10 \%$ phosphatidylserine and either CD47 or the inactive CD47 ${ }^{\mathrm{F} 37 \mathrm{D}, \mathrm{T115K}}$. Data was normalized to the maximum bead eating observed in that replicate. The complete, pooled data is shown in Supplementary Figure 1E. Dots and error bars denote the mean and standard error of independent replicates. ${ }^{* * *}$ indicates $p<0.0005$ by a Kruskal-Wallis test on the pooled data (B and E). Scale bar denotes $5 \mu \mathrm{m}$ in this and 
381 (A) SIRPA-GFP (top; green in merge) is depleted from the base of the phagocytic cup 382 (arrow) when a macrophage engulfs a bead functionalized with $\lg G$ and CD47 $537 \mathrm{D}$,

383 T115K, which cannot bind SIRPA (left; supported lipid bilayer, magenta). SIRPA is not 384 depleted when CD47 is present (IgG+CD47, right). Graph depicts the ratio of SIRPA385 GFP at the phagocytic cup/cell cortex for individual phagocytic cups. (B) A schematic 386 shows the chimeric SIRPA constructs in this figure. Full length SIRPA is on the right, 387 FRB ${ }^{\text {ext }}$-SIRPA is in the center and FcRI ${ }^{\text {ext }}$-SIRPA ${ }^{\text {int }}$-GFP is on the left. (C) SIRPA-GFP, 388 FRB ${ }^{\text {ext }}$-SIRPA-GFP and FCRI ${ }^{\text {ext_SIRPA }}{ }^{\text {int }}$-GFP fluorescence is shown at cell-bead 389 contacts (arrow). (D) Graph depicts the ratio of GFP fluorescence at the synapse 390 (arrow in C) compared to the cortex for the indicated SIRPA chimeras. (E) A graph depicts the average number of internalized IgG beads per macrophage expressing the chimeric SIRPA constructs schematized in (B), normalized to macrophages expressing only a membrane-tethered GFP (GFP-CAAX). (F) Schematic (left) shows a system for inducible recruitment of the SIRPA intracellular domain to the phagocytic cup. Recruiting SIRPA to the phagocytic cup suppresses engulfment compared to soluble SIRPA or compared to wild-type macrophages treated with rapamycin (normalized to uninfected macrophages). (G) The graph shows the number of beads engulfed by uninfected, SIRPA-GFP or FRB ${ }^{\text {ext }}$-SIRPA expressing macrophages normalized to uninfected cells. In $A$ and $D$, dots represent individual cups, red lines show mean $\pm S D$ and data is pooled from three independent experiments. In $E, F$ and $G$, dots show the average from an independent replicate with the error bars denoting SEM for that replicate. The complete pooled data showing the number of beads eaten per macrophage is shown in Figure S2. ${ }^{* * *}$ denotes $p<0.0005,{ }^{* *}$ denotes $p<0.005$ and

* denotes $p<0.05$ as determined by a Student's $T$ test (A, D) or a Kruskal-Wallis test on the pooled data from all three replicates $(E, F, G)$.

Figure 3: CD47 prevents integrin activation

(A) Still images from a TIRF microscopy timelapse show that macrophages form IgG (black) microclusters as they spread across an IgG bilayer (top). Adding CD47 to the bilayer inhibits cell spreading (bottom; graphed on right, average area of contact from $\mathrm{n} \geq 11$ cells \pm SEM, pooled from three separate experiments). (B) TIRF images show 
412 the cell membrane (mCherry-CAAX; white) of macrophages engaging with an IgG 413 (left) or IgG and CD47 (right) bilayer. Graphs depict the average number of cells seen 414 contacting the bilayer after $10 \mathrm{~min}$ (center) and the average area of cell contact (right).

415 Each dot represents an individual field of view (center) or cell (right) pooled from three 416 independent experiments. (C) Diagram shows that IgG binding activates Fc Receptor, 417 which triggers downstream signaling events including inside-out activation of integrins. 418 Blocking integrin activation using a function-blocking antibody (2E6) targeting the $\beta 2$ 419 integrin subunit decreased the efficiency of engulfment (graphed in center panel, 420 normalized to the isotype control, with error bars denoting SEM of each replicate). (D) 421 Immunofluorescence images show phosphopaxillin (top; green in merge) and F-actin 422 (center; magenta in merge; visualized with phalloidin) at the phagocytic cup of an IgG 423 coated bead (left) or an IgG- and CD47-coated bead (right). Graphs show the ratio of

424 phosphopaxilin intensity at the phagocytic cup/cell cortex. Each dot represents an 425 individual phagocytic cup; lines denote the mean \pm SD. The non-activating CD47 F37D, $426 \mathrm{~T}^{\mathrm{T} 15 \mathrm{~K}}$ was used as a control on bilayers lacking CD47. *** denotes $\mathrm{p}<0.0005$, ** 427 denotes $p<0.005$, and * denotes $p<0.05$ as determined by Student's $T$ test $(A, B$ and 428 D) or a Kruskal-Wallis test on the pooled data (C).

430 Figure 4: Bypassing inside out activation of integrin eliminates the effect of 431 CD47.

432 (A) The schematic shows a simplified signaling diagram. If CD47 and SIRPA act 433 upstream of integrin, then providing an alternate means of integrin activation $\left(\mathrm{Mn}^{2+}\right.$ or 434 ICAM) should eliminate the effect of CD47. (B) Macrophages were treated with $1 \mathrm{mM}$ $435 \mathrm{Mn}^{2+}$ and fed beads with $\operatorname{lgG}$ and either CD47 (red) or the non-signaling CD47 ${ }^{\mathrm{F} 37 \mathrm{D} \text {, }}$ $436 \mathrm{~T}^{\mathrm{T} 15 \mathrm{~K}}$ (green). Bars denote the average number of beads eaten from the pooled data of 437 three independent replicates \pm SEM. (C) Beads were incubated with the indicated 438 concentration of $\mathrm{lgG}$ and added to macrophages. Treatment with $\mathrm{Mn}^{2+}$ did not 439 dramatically enhance engulfment (black, compared to grey). Dots represent the 440 average number of beads eaten \pm SEM in one data set representative of three 441 experiments. (D) Immunofluorescence shows that adding ICAM (10 nM coupling 442 concentration) to IgG + CD47 beads rescues phosphopaxillin (top; green in merge, 
443 bottom) at the phagocytic cup. Compare to data displayed in Figure 3D ( $p<0.0005$ for 444 phosphopaxilin with ICAM and CD47 compared to CD47 alone). (E) Beads were 445 functionalized with $\lg$ and either CD47 (red) or the non-signaling CD47 ${ }^{\text {F37D, T115K }}$ 446 (green). Adding ICAM to the beads abrogated the effect of CD47 (center) but did not 447 stimulate engulfment without IgG (right). (F) ICAM also rescued actin accumulation at 448 the phagocytic cup as measured by the ratio of phalloidin fluorescence at the cup to 449 the cell cortex. $(G)$ Bone marrow-derived macrophages expressing a membrane 450 tethered GFP (GFP-CAAX) were incubated with L1210 murine leukemia cells 451 expressing H2B-mCherry. Treating with $100 \mu \mathrm{M}$ manganese allowed for engulfment of 452 whole cancer cells. These images correspond to frames from Movie S3. $(H)$ The 453 percent of macrophages engulfing a cancer cell during an $8 \mathrm{hr}$ timelapse is graphed. 454 Each dot represents an independent replicate, with lines denoting mean \pm SEM. (I) 455 Model figure shows that in the absence of CD47 (left), SIRPA is segregated away 456 from the phagocytic synapse and Fc Receptor binding triggers inside out activation of 457 integrin. When CD47 is present (right), SIRPA localizes to the synapse and inhibits 458 integrin activation. ${ }^{* * *}$ denotes $p<0.0005,{ }^{* *}$ denotes $p<0.005$ and n.s. denotes $p>0.05$ 459 as determined by a Kruskal-Wallis test (B, E), Ordinary One-way ANOVA (D, F) or 460 Fisher Exact $(\mathrm{H})$ on the pooled data from all three replicates. 


\section{Materials and Methods}

Cell culture

RAW264.7 macrophages were provided by the ATCC and certified mycoplasma-free. The cells were cultured in DMEM (Gibco, Catalog \#11965-092) supplemented with $1 \mathrm{x}$ 467 Pen-Strep-Glutamine (Corning, Catalog \#30-009 Cl) $1 \mathrm{mM}$ sodium pyruvate (Gibco, 468 Catalog \#11360-070) and 10\% heat inactivated fetal bovine serum (Atlanta Biologicals, 469 Catalog \#S11150H). To keep variation to a minimum, cells were discarded after 20 470 passages. L1210 cells were also acquired from the ATCC.

471 J774A.1 macrophages were provided by the UCSF cell culture facility. J774A.1 and 472 293T cells were tested for mycoplasma using the Lonza MycoAlert Detection Kit (Lonza, 473 Catalog\# LT07-318) and control set (Lonza, Catalog \#LT07-518).

474 Bone marrow derived macrophages were generated from the hips and long bones of 475 C57BL/6J mice as previously described (Weischenfeldt and Porse, 2008) except that 476 purified $25 \mathrm{ng} / \mathrm{ml}$ M-CSF (Peprotech, Catalog \# 315-02) was used.

\section{Constructs and antibodies}

479 All relevant information is provided in the STAR methods table, including a detailed 480 description of the amino acid sequence of each construct and the catalog number of all 481 antibodies.

\section{Lentivirus production and infection}

All constructs were expressed in RAW264.7 using lentiviral infection. Lentivirus was produced in HEK293T cells transfected with pMD2.G (a gift from Didier Tronon,

486 Addgene plasmid \# 12259 containing the VSV-G envelope protein), pCMV-dR8.91 487 (since replaced by second generation compatible pCMV-dR8.2, Addgene plasmid 488 \#8455), and a lentiviral backbone vector containing the construct of interest (derived 489 from pHRSIN-CSGW, see STAR methods) using lipofectamine LTX (Invitrogen, Catalog 490 \# 15338-100). Constructs are described in detail in the Key Resources Table. The 491 media was harvested 72 hours post-infection, filtered through a $0.45 \mu \mathrm{m}$ filter and 492 concentrated using LentiX (Takara Biosciences). After addition of the concentrated 
493 virus, cells were centrifuged at $2000 \mathrm{xg}$ for $45 \mathrm{~min}$ at $37^{\circ} \mathrm{C}$. Cells were analyzed a

494 minimum of $60 \mathrm{hr}$ later.

\section{Supported lipid bilayer assembly}

497 SUV preparation

498 The following chloroform-suspended lipids were mixed and desiccated overnight to 499 remove chloroform: 96.8\% POPC (Avanti, Catalog \# 850457), 2\% Ni ${ }^{2+}$-DGS-NTA 500 (Avanti, Catalog \# 790404), 1\% biotinyl cap PE (Avanti, Catalog \# 870273), 0.1\% 501 PEG5000-PE (Avanti, Catalog \# 880230, and 0.1\% atto390-DOPE (ATTO-TEC GmbH, 502 Catalog \# AD 390-161). The lipid sheets were resuspended in PBS, pH7.2 (Gibco, 503 Catalog \# 20012050) and stored under argon. The lipids were broken into small 504 unilamelar vesicles via several rounds of freeze-thaws. The mixture was cleared using 505 ultracentrifugation (TLA120.1 rotor, 35,000 rpm / 53,227 x g, $35 \mathrm{~min}, 4^{\circ} \mathrm{C}$ ). The lipids 506 were then stored at $4^{\circ} \mathrm{C}$ under argon for up to two weeks.

Planar bilayer preparation for TIRF microscopy

509 Ibidi coverslips (catolog \#10812) were RCA cleaned. Supported lipid bilayers were 510 assembled in custom plasma cleaned PDMS (Dow Corning, catalog \# 3097366-0516 511 and 3097358-1004) chambers at room temperature for 1 hour. Bilayers were blocked 512 with $0.2 \%$ casein (Sigma, catalog \# C5890) in PBS. Proteins were coupled to the bilayer

513 for 45 min. Imaging was conducted in HEPES buffered saline (20 mM HEPEs, 135 mM $514 \mathrm{NaCl}, 4 \mathrm{mM} \mathrm{KCl}, 10 \mathrm{mM}$ glucose, $1 \mathrm{mM} \mathrm{CaCl}_{2}, 0.5 \mathrm{mM} \mathrm{MgCl}_{2}$ ). Bilayers were assessed 515 for mobility by either photobleaching or monitoring the mobility of single particles.

\section{Bead preparation}

$5188.6^{\star} 10^{8}$ silica beads with a $5.02 \mu \mathrm{m}$ diameter $(10 \mu \mathrm{l}$ of $10 \%$ solids, Bangs Labs, 519 Catalog \# SS05N) were washed three times with PBS, mixed with 1mM SUVs in PBS 520 and incubated at room temperature for $0.5-2 \mathrm{hr}$ with end-over-end mixing to allow for 521 bilayer formation. Beads were then washed three times with PBS to remove excess 522 SUVs and incubated in $100 \mu \mathrm{l}$ of 0.2\% casein (Sigma, catalog \# C5890) in PBS for 15 523 min before protein coupling. Unless otherwise indicated, anti-biotin AlexaFluor647-lgG 
524 (Jackson ImmunoResearch Laboratories Catalog \# 200-602-211, Lot \# 137445) was

525 added between 3 and $30 \mathrm{nM}$, always using the lowest IgG concentration that triggered

526 engulfment. Purified $\mathrm{CD} 47^{\mathrm{ext}}-\mathrm{His} \mathrm{s}_{10}$ was added at $1 \mathrm{~nm}$. Proteins were coupled to the

527 bilayer for $1 \mathrm{hr}$ at room temperature with end-over-end mixing.

Protein density estimation

530 Given the high affinity of $\mathrm{His}_{10}$ for $\mathrm{Ni}^{2+}$-DGS-NTA (0.6 nM (Hui and Vale, 2014)), and 531 antibody-antigen interactions, we expect close to $100 \%$ coupling efficiency (Hui and 532 Vale, 2014). Complete coupling would result in 600 molecules $/ \mu \mathrm{m}^{2}$ CD47 and 300 533 molecules $/ \mu \mathrm{m}^{2} \mathrm{IgG}$ for the $3 \mathrm{nM}$ coupling condition. This is well within the range of 534 CD47 on the surface of a cancer cell (Figure S1). In addition, to estimate the amount of $535 \mathrm{lg}$ bound to each bead, we compared the fluorescence of $\lg G$ on the bead surface to 536 calibrated fluorescent beads (Quantum AlexaFluor 647, Bangs Lab) using confocal 537 microscopy. Using this method, we measured $200-360$ molecules $/ \mu \mathrm{m}^{2}$ of $\mathrm{IgG}$, which is 538 consistent with the theoretical prediction of near complete coupling.

\section{Protein Purification}

$\mathrm{His}_{10}-\mathrm{CD} 47^{\mathrm{ext}}, \mathrm{His}_{10}-\mathrm{CD} 47^{\mathrm{ext} \text { F37D, T115K }}$ (aa40-182; Uniprot Q61735) and ICAM-tagBFP-

$542 \mathrm{His}_{10}$ (O'Donoghue et al., 2013) were expressed in SF9 or HiFive cells using the Bac-to-

543 Bac baculovirus system as described previously (Hui and Vale, 2014). Briefly, the N-

544 terminal extracellular domain of CD47 was cloned into a modified pFastBac HT A with 545 an upstream signal peptide from chicken RPTPo (Chang et al., 2016). Insect cell media 546 containing secreted proteins was harvested $72 \mathrm{hr}$ after infection with baculovirus. His $\mathrm{s}_{10}$ 547 proteins were purified by using Ni-NTA agarose (Qiagen, Catalog \# 30230), followed by 548 size exclusion chromatography using a Superdex 200 10/300 GL column (GE 549 Healthcare, Catalog \# 17517501). The purification buffer was $30 \mathrm{mM}$ Hepes pH 7.4, 150 $550 \mathrm{mM} \mathrm{NaCl}, 2 \mathrm{mM} \mathrm{MgCl}$, $5 \%$ glycerol (CD47) or $150 \mathrm{mM} \mathrm{NaCl}, 50 \mathrm{mM}$ Hepes $\mathrm{pH} 7.4,5 \%$ 551 glycerol, 2 mM TCEP (ICAM). 
554 Macrophages were fixed in 4\% PFA for $15 \mathrm{~min}$, then permeabilized and blocked with

$5550.1 \%$ BSA in PBS with $0.5 \%$ Tween 20 . The cells were incubated with the 556 phosphopaxillin antibody at 1:50 dilution at $4^{\circ} \mathrm{C}$ overnight before incubating with Alexa

557 Fluor 555 anti-rabbit secondary (21428), Alexa Fluor 488 phalloidin (A12379).

$559 \quad \beta 2$ integrin block and Fab generation

560 To disrupt integrin function, the 2E6 anti- $\beta 2$ integrin antibody (ThermoFisher, MA1805)

561 or isotype control (ThermoFisher, 16-4888-81) was added to macrophages at $10 \mu \mathrm{g} / \mathrm{ml}$ 56230 minutes before IgG-opsonized beads. To eliminate any effects of the Fc domain, we 563 generated Fabs from these antibodies using the Pierce Fab separation kit 564 (ThermoFisher 44985).

\section{Whole cell internalization assay}

56730,000 macrophages infected with GFP-CAAX were plated in a 96-well glass bottom 568 MatriPlate (Brooks, Catalog \# MGB096-1-2-LG-L). 2 hours prior to imaging, cells were 569 washed into serum-free, phenol free DMEM for imaging. Manganese (SigmaAldrich, 570 M8054) was added at $100 \mu \mathrm{M} 30$ min prior to imaging. or CD47 function-blocking 571 antibody clone miap301 (Biolegend, 127520) was used at $10 \mathrm{mg} / \mathrm{ml}$. 100,000 H2B572 mCherry expressing L1210 cells were added and the co-culture was imaged for $8 \mathrm{hr}$.

\section{Microscopy and analysis}

575 Images were acquired on a spinning disc confocal microscope (Nikon Ti-Eclipse 576 inverted microscope with a Yokogawa spinning disk unit and an Andor iXon EM-CCD 577 camera) equipped with a $40 \times 0.95 \mathrm{NA}$ air and a $100 \times 1.49 \mathrm{NA}$ oil immersion objective. 578 The microscope was controlled using $\mu$ Manager. For TIRF imaging, images were 579 acquired on the same microscope with a motorized TIRF arm, but using a Hamamatsu 580 Flash 4.0 camera and the $100 \times 1.49$ NA oil immersion objective.

\section{Quantification of engulfment}

$583 \quad 30,000$ macrophages in one well of a 96-well glass bottom MatriPlate (Brooks, Catalog 584 \# MGB096-1-2-LG-L) between 12 and $24 \mathrm{hr}$ prior to the experiment. Macrophages 
585 remained in culture media (DMEM with 10\% heat inactivated serum) throughout the

586 experiment. Unless otherwise indicated, $\sim 1 \times 10^{7}$ beads were added to well and

587 engulfment was allowed to proceed for $30 \mathrm{~min}$. Cells were fixed with $4 \%$ PFA and

588 stained with CellMask (ThermoFisher, catalog \# C10045) without membrane

589 permeabilization to label cell boundaries. Images were acquired using the High Content

590 Screening (HCS) Site Generator plugin in $\mu$ Manager (Edelstein et al., 2010).

Quantification of synapse intensity of phosphoPaxillin, actin and SIRPA 593 constructs

594 Phagocytic cups were selected for analysis based on the presence of clustered $\lg G$ at 595 the cup base (SIRPA chimeras) or clear initiation of membrane extensions around the 596 phagocytic target (actin, phosphopaxillin). The phagocytic cup and the cell cortex were 597 traced with a line 3 pixels wide at the Z-slice with the clearest cross section of the cup.

598 The average background intensity was measured in an adjacent region and subtracted 599 from each measurement.

\section{Quantification of the cell-bilayer contact area}

602 For $3 \mathrm{~A}$, time-lapse images of macrophages interacting with an $\lg \mathrm{G}$ or $\lg \mathrm{G}+\mathrm{CD} 47$ 603 bilayer were acquired using TIRF microscopy as described above. Macrophages were 604 removed from their culture dish using 5\% EDTA in PBS, two times washed and 605 resuspended in the HEPES imaging buffer (20 mM HEPEs, $135 \mathrm{mM} \mathrm{NaCl}, 4 \mathrm{mM} \mathrm{KCl}$, $60610 \mathrm{mM}$ glucose, $1 \mathrm{mM} \mathrm{CaCl}_{2}, 0.5 \mathrm{mM} \mathrm{MgCl}_{2}$ ) before being added to the TIRF chamber. 607 The area of the cell contacting the bilayer was traced in ImageJ beginning with the first 608 frame where the cell can be detected. Only cells with mobile IgG clusters were included. 609 For 3B, the number of macrophage-bilayer contacts and the area was quantified in still 610 images of live cells between 10 and 15 min after cells were added to the bilayer. All 611 cells were included.

612

\section{Statistics}

614 Statistical analysis was performed in Prism 8 (GraphPad, Inc). The statistical test used 615 is indicated in the relevant figure legend. 


\section{Supplemental Figure Legends}

618 Figure S1, related to Figure 1: A reconstitution system for studying CD47-SIRPA 619 signaling

620 (A) SDS page gel shows the N-terminal extracellular domain of murine CD47 purified 621 from insect cells using a C-terminal His 10. $_{10}$ (B) Beads coated in supported lipid bilayers 622 were incubated with the indicated concentration of anti-biotin IgG. The fluorescent 623 intensity of Alexa Fluor 647-IgG on the bead was measured to ensure that the binding 624 of IgG increased with higher coupling concentrations. (C) The estimated surface density 625 of CD47 on red blood cells (Gardner et al., 1991; Mouro-Chanteloup et al., 2003), T 626 cells (Subramanian et al., 2006), cancer cells (Dheilly et al., 2017; Jaiswal et al., 2009; 627 Michaels et al., 2017) and the beads used in this study. (D) IgG surface density was 628 held constant while CD47 density was titrated. The 1 nM CD47 coupling concentration 629 was selected for use throughout this study. (E) Histograms depict the fraction of 630 macrophages engulfing the indicated number of phosphatidylserine beads. The 631 RAW264.7 histograms correspond to the replicates depictured in Figure 1E. RAW264.7 632 engulfment was measured after $30 \mathrm{~min}$ and J774A.1 was measured after $90 \mathrm{~min}$.

634 Figure S2, related to Figure 2: Forcing SIRPA into the macrophage-target synapse 635 suppresses engulfment

636 (A) Schematic depicts TIRF imaging. (B) TIRF microscopy of J774A.1 macrophages 637 encountering a 10\% phosphatidylserine bilayer reveals that SIRPA-GFP is depleted at 638 the center off the cell-bilayer synapse (top; yellow arrow compared to cyan arrow). 639 Macrophages did not form this zone of depletion when encountering a bilayer containing 640 both phosphatidylserine and CD47 (bottom). The ratio of SIRPA-GFP fluorescent 641 intensity at the cell center/cell edge is quantified on the right. Each dot represents an 642 individual cell and data is pooled from 3 independent experiments. Lines denote the 643 mean \pm SD. ${ }^{* * *}$ denotes $p<0.0005$ by Student's T test. (C) SIRPA-GFP and the chimeric

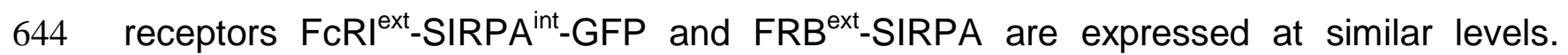
645 Fluorescent intensity was normalized to the average intensity of SIRPA-GFP in that 646 experiment. Each dot represents an individual cell and data is pooled from 3 
647 independent experiments. Lines denote the mean \pm SD. (D, E and F) Histograms depict

648 the fraction of macrophages engulfing the indicated number of IgG-bound beads. The 649 average number of beads per cell is shown \pm SEM. This data corresponds to 1E (D), 1F 650 (E) and $1 G(F)$. For all panels, data is pooled from three data is pooled from 3 651 independent experiments. Lines denote the mean \pm SD.

653 Figure S3, related to Figure 3: CD47 does not affect FcR activation and Syk 654 recruitment.

655 (A) TIRF microscopy shows that macrophages are able to form IgG microclusters (left; 656 cyan in merged image) that recruit Syk (middle; magenta in merged image) if CD47 is 657 absent (top) or present (bottom). Inset shows the boxed region of the image above. The 658 linescan shows the fluorescent intensity of Alexa Fluor 647-IgG and Syk-mCherry at the 659 indicated position (white arrow). Intensity was normalized so that 1 is the highest 660 observed intensity and 0 is background. The fraction of cells able to form IgG clusters 661 and recruit Syk is displayed on the far right. Each dot represents the percent from an 662 independent experiment $(n \geq 20$ per replicate) and the lines denote mean $\pm S D$. (B) 663 TIRF microscopy shows that, in the presence of CD47, SIRPA (green) does not co664 localize with IgG clusters (cyan; arrowheads). Inset shows the boxed region in the 665 above image. The linescan shows the fluorescent intensity of Alexa Fluor 647-IgG and 666 SIRPA-GFP at the position indicated by a white arrow. (C) Macrophages were 667 incubated with a Fab generated from the $\beta 2$ function-blocking antibody (2E6, red) or 668 from an isotype control (green). The pooled data from three independent replicates is 669 graphed with error bars denoting SEM. ** indicates $\mathrm{p}<0.005$ by Kruskal-Wallis test.

671 Figure S4, related to Figure 4: Manganese does not affect L1210 viability

$672 \mathrm{~L} 1210$ cells were serum starved for $2 \mathrm{hrs}$, then treated with $100 \mu \mathrm{M}$ manganese for 6 $673 \mathrm{hrs}$ as in $2 \mathrm{H}$. The percent of cells that bound high levels of annexin, indicating 674 phosphatidylserine exposure and the initiation of apoptosis, was measured by flow 675 cytometry.

677 Movie S1: Macrophage encounters IgG bound to a supported lipid bilayer. 
678 TIRF imaging (see schematic in Figure S2) shows Alexa Fluor 647-lgG (black) in the

679 supported lipid bilayer as a macrophage engages with an IgG-bound target. Frames

680 were acquired every $20 \mathrm{sec}$ and time is indicated in the top left. Scale bar denotes 5

$681 \mu \mathrm{m}$.

682

683 Movie S2: Macrophage encounters IgG and CD47 bound to a supported lipid

684 bilayer.

685 TIRF imaging shows Alexa Fluor 647-lgG (black) in the supported lipid bilayer as a

686 macrophage engages with an IgG and CD47-bound target. Frames were acquired every

$68720 \mathrm{sec}$ and time is indicated in the top left. Scale bar denotes $5 \mu \mathrm{m}$.

689 Movie S3: An Mn-treated macrophage encounters an L1210 leukemia cell

690 A macrophage infected with GFP- CAAX encounters an L1210 leukemia cell labeled

691 with H2B-mCherry. In the presence of $100 \mu \mathrm{M} \mathrm{Mn}^{2+}$ the macrophage is able to engulf

692 the cancer cell. Images were acquired every $5 \mathrm{~min}$ for $140 \mathrm{~min}$. The field of view is 53

$693 \mu \mathrm{m}$ by $53 \mu \mathrm{m}$.

694 


\section{References}

696 Advani, R., Flinn, I., Popplewell, L., Forero, A., Bartlett, N.L., Ghosh, N., Kline, J.,

697 Roschewski, M., LaCasce, A., Collins, G.P., et al. (2018). CD47 Blockade by Hu5F9-G4

698 and Rituximab in Non-Hodgkin's Lymphoma. N. Engl. J. Med. 379, 1711-1721.

699 Alenghat, F.J., Baca, Q.J., Rubin, N.T., Pao, L.I., Matozaki, T., Lowell, C.A., Golan,

700 D.E., Neel, B.G., and Swanson, K.D. (2012). Macrophages require Skap2 and Sirpa for

701 integrin-stimulated cytoskeletal rearrangement. J. Cell Sci. 125, 5535-5545.

702 Barclay, A.N., and Brown, M.H. (2006). The SIRP family of receptors and immune

703 regulation. Nat. Rev. Immunol. 6, 457-464.

704 Birge, R.B., Boeltz, S., Kumar, S., Carlson, J., Wanderley, J., Calianese, D., Barcinski,

705 M., Brekken, R.A., Huang, X., Hutchins, J.T., et al. (2016). Phosphatidylserine is a

706 global immunosuppressive signal in efferocytosis, infectious disease, and cancer. Cell

707 Death Differ. 23, 962-978.

708 Campbell, H., Heidema, C., Pilarczyk, D.G., and DeMali, K.A. (2018). SHP-2 is

709 activated in response to force on E-cadherin and dephosphorylates vinculin Y822. J.

710 Cell Sci. 131, jcs216648.

711 Caron, E., Self, A.J., and Hall, A. (2000). The GTPase Rap1 controls functional

712 activation of macrophage integrin alphaMbeta2 by LPS and other inflammatory

713 mediators. Curr. Biol. 10, 974-978.

714 Chang, V.T., Fernandes, R.A., Ganzinger, K.A., Lee, S.F., Siebold, C., McColl, J.,

715 Jönsson, P., Palayret, M., Harlos, K., Coles, C.H., et al. (2016). Initiation of T cell

716 signaling by CD45 segregation at "close contacts". Nat. Immunol. 17, 574-582.

717 Chao, M.P., Alizadeh, A.A., Tang, C., Myklebust, J.H., Varghese, B., Gill, S., Jan, M.,

718 Cha, A.C., Chan, C.K., Tan, B.T., et al. (2010a). Anti-CD47 Antibody Synergizes with

719 Rituximab to Promote Phagocytosis and Eradicate Non-Hodgkin Lymphoma. Cell 142,

$720 \quad 699-713$.

721 Chao, M.P., Jaiswal, S., Weissman-Tsukamoto, R., Alizadeh, A.A., Gentles, A.J.,

722 Volkmer, J., Weiskopf, K., Willingham, S.B., Raveh, T., Park, C.Y., et al. (2010b).

723 Calreticulin Is the Dominant Pro-Phagocytic Signal on Multiple Human Cancers and Is

724 Counterbalanced by CD47. Sci. Transl. Med. 2, 63ra94-63ra94.

725 Chao, M.P., Weissman, I.L., and Majeti, R. (2012). The CD47-SIRPa pathway in cancer 
726 immune evasion and potential therapeutic implications. Curr. Opin. Immunol. 24, 225727232.

728 Chen, J., Zhong, M.-C., Guo, H., Davidson, D., Mishel, S., Lu, Y., Rhee, I., Pérez-

729 Quintero, L.-A., Zhang, S., Cruz-Munoz, M.-E., et al. (2017). SLAMF7 is critical for 730 phagocytosis of haematopoietic tumour cells via Mac-1 integrin. Nature 544, 493-497.

731 Dheilly, E., Moine, V., Broyer, L., Salgado-Pires, S., Johnson, Z., Papaioannou, A.,

732 Cons, L., Calloud, S., Majocchi, S., Nelson, R., et al. (2017). Selective Blockade of the 733 Ubiquitous Checkpoint Receptor CD47 Is Enabled by Dual-Targeting Bispecific

734 Antibodies. Mol. Ther. 25, 523-533.

735 Dransfield, I., Cabanas, C., Craig, A., and Hogg, N. (1992). Divalent Cation Regulation 736 of the Function of the Leukocyte Integrin LFA1.

737 Dupuy, A.G., and Caron, E. (2008). Integrin-dependent phagocytosis: spreading from 738 microadhesion to new concepts. J. Cell Sci. 121, 1773-1783.

739 Edelstein, A., Amodaj, N., Hoover, K., Vale, R., and Stuurman, N. (2010). Computer 740 control of microscopes using manager. Curr. Protoc. Mol. Biol. Chapter 14, Unit14 20.

741 Fadok, V.A., Voelker, D.R., Campbell, P.A., Cohen, J.J., Bratton, D.L., and Henson, 742 P.M. (1992). Exposure of phosphatidylserine on the surface of apoptotic lymphocytes

743 triggers specific recognition and removal by macrophages. J. Immunol. 148, 22077442216.

745 Freeman, S.A., and Grinstein, S. (2014). Phagocytosis: Receptors, signal integration, 746 and the cytoskeleton. Immunol. Rev. 262, 193-215.

747 Freeman, S.A., Goyette, J., Furuya, W., Woods, E.C., Bertozzi, C.R., Bergmeier, W., 748 Hinz, B., Van Der Merwe, P.A., Das, R., and Grinstein, S. (2016). Integrins Form an 749 Expanding Diffusional Barrier that Coordinates Phagocytosis. Cell 164, 128-140.

750 Fujioka, Y., Matozaki, T., Noguchi, T., Iwamatsu, A., Yamao, T., Takahashi, N., Tsuda, 751 M., Takada, T., and Kasuga, M. (1996). A novel membrane glycoprotein, SHPS-1, that 752 binds the SH2-domain-containing protein tyrosine phosphatase SHP-2 in response to 753 mitogens and cell adhesion. Mol. Cell. Biol. 16, 6887-6899.

754 Gardai, S.J., McPhillips, K.A., Frasch, S.C., Janssen, W.J., Starefeldt, A., Murphy755 Ullrich, J.E., Bratton, D.L., Oldenborg, P.-A.A., Michalak, M., and Henson, P.M. (2005). 756 Cell-surface calreticulin initiates clearance of viable or apoptotic cells through trans- 
757 activation of LRP on the phagocyte. Cell 123, 321-334.

758 Gardner, B., Anstee, D.J., Mawby, W.J., Tanner, M.J., and von dem Borne, A.E. (1991).

759 The abundance and organization of polypeptides associated with antigens of the $\mathrm{Rh}$

760 blood group system. Transfus. Med. 1, 77-85.

761 Geiger, B., Spatz, J.P., and Bershadsky, A.D. (2009). Environmental sensing through

762 focal adhesions. Nat. Rev. Mol. Cell Biol. 10, 21-33.

763 Gholamin, S., Mitra, S.S., Feroze, A.H., Liu, J., Kahn, S.A., Zhang, M., Esparza, R.,

764 Richard, C., Ramaswamy, V., Remke, M., et al. (2017). Disrupting the CD47-SIRPa

765 anti-phagocytic axis by a humanized anti-CD47 antibody is an efficacious treatment for

766 malignant pediatric brain tumors. Sci. Transl. Med. 9, eaaf2968.

767 Goodridge, H.S., Reyes, C.N., Becker, C.A., Katsumoto, T.R., Ma, J., Wolf, A.J., Bose,

768 N., Chan, A.S.H., Magee, A.S., Danielson, M.E., et al. (2011). Activation of the innate

769 immune receptor Dectin-1 upon formation of a 'phagocytic synapse.' Nature 472, 471-

770475.

771 Hatherley, D., Graham, S.C., Turner, J., Harlos, K., Stuart, D.I., and Barclay, A.N.

772 (2008). Paired Receptor Specificity Explained by Structures of Signal Regulatory

773 Proteins Alone and Complexed with CD47. Mol. Cell 31, 266-277.

774 Hui, E., and Vale, R.D. (2014). In vitro membrane reconstitution of the T-cell receptor

775 proximal signaling network. Nat. Struct. Mol. Biol. 21, 133-142.

776 Inagaki, K., Yamao, T., Noguchi, T., Matozaki, T., Fukunaga, K., Takada, T., Hosooka,

777 T., Akira, S., and Kasuga, M. (2000). SHPS-1 regulates integrin-mediated cytoskeletal

778 reorganization and cell motility. EMBO J. 19, 6721-6731.

779 Jaiswal, S., Jamieson, C.H.M., Pang, W.W., Park, C.Y., Chao, M.P., Majeti, R., Traver,

780 D., van Rooijen, N., and Weissman, I.L. (2009). CD47 Is Upregulated on Circulating

781 Hematopoietic Stem Cells and Leukemia Cells to Avoid Phagocytosis. Cell 138, $271-$

782285.

783 James, J.R., and Vale, R.D. (2012). Biophysical mechanism of T-cell receptor triggering

784 in a reconstituted system. Nature 487, 64-69.

785 Jiang, P., Lagenaur, C.F., and Narayanan, V. (1999). Integrin-associated protein is a

786 ligand for the P84 neural adhesion molecule. J. Biol. Chem. 274, 559-562.

787 Jones, S.L., Knaus, U.G., Bokoch, G.M., and Brown, E.J. (1998). Two signaling 
788 mechanisms for activation of alphaM beta2 avidity in polymorphonuclear neutrophils. J.

789 Biol. Chem. 273, 10556-10566.

790 Lin, J., Kurilova, S., Scott, B.L., Bosworth, E., Iverson, B.E., Bailey, E.M., and Hoppe,

791 A.D. (2016). TIRF imaging of Fc gamma receptor microclusters dynamics and signaling

792 on macrophages during frustrated phagocytosis. BMC Immunol. 17, 5.

793 Liu, D.Q., Li, L.M., Guo, Y.L., Bai, R., Wang, C., Bian, Z., Zhang, C.Y., and Zen, K.

794 (2008). Signal regulatory protein a negatively regulates $\beta 2$ integrin-mediated monocyte

795 adhesion, transendothelial migration and phagocytosis. PLoS One 3.

796 Liu, X., Pu, Y., Cron, K., Deng, L., Kline, J., Frazier, W.A., Xu, H., Peng, H., Fu, Y.-X.,

797 and Xu, M.M. (2015). CD47 blockade triggers T cell-mediated destruction of

798 immunogenic tumors. Nat. Med. 21, 1209-1215.

799 Majeti, R., Chao, M.P., Alizadeh, A.A., Pang, W.W., Jaiswal, S., Gibbs, K.D., van

800 Rooijen, N., and Weissman, I.L. (2009). CD47 Is an Adverse Prognostic Factor and

801 Therapeutic Antibody Target on Human Acute Myeloid Leukemia Stem Cells. Cell 138,

802 286-299.

803 Matlung, H.L., Babes, L., Zhao, X.W., van Houdt, M., Treffers, L.W., van Rees, D.J.,

804 Franke, K., Schornagel, K., Verkuijlen, P., Janssen, H., et al. (2018). Neutrophils Kill

805 Antibody-Opsonized Cancer Cells by Trogoptosis. Cell Rep. 23, 3946-3959.e6.

806 Michaels, A.D., Newhook, T.E., Adair, S.J., Morioka, S., Goudreau, B.J., Nagdas, S.,

807 Mullen, M.G., Persily, J.B., Bullock, T.N.J., Slingluffjr, C.L., et al. (2017). Cancer

808 Therapy: Preclinical CD47 Blockade as an Adjuvant Immunotherapy for Resectable

809 Pancreatic Cancer.

810 Motegi, S. -i., Okazawa, H., Ohnishi, H., Sato, R., Kaneko, Y., Kobayashi, H.,

811 Tomizawa, K., Ito, T., Honma, N., Bühring, H., et al. (2003). Role of the CD47-SHPS-1

812 system in regulation of cell migration. EMBO J. 22, 2634-2644.

813 Mouro-Chanteloup, I., Delaunay, J., Gane, P., Nicolas, V., Johansen, M., Brown, E.J.,

814 Peters, L.L., Van Kim, C. Le, Cartron, J.P., and Colin, Y. (2003). Evidence that the red

815 cell skeleton protein 4.2 interacts with the Rh membrane complex member CD47. Blood

$816101,338-344$.

817 Noguchi, T., Matozaki, T., Fujioka, Y., Yamao, T., Tsuda, M., Takada, T., and Kasuga,

818 M. (1996). Characterization of a 115-kDa protein that binds to SH-PTP2, a protein- 
819 tyrosine phosphatase with Src homology 2 domains, in Chinese hamster ovary cells. J.

820 Biol. Chem. 271, 27652-27658.

821 O’Donoghue, G.P., Pielak, R.M., Smoligovets, A.A., Lin, J.J., and Groves, J.T. (2013).

822 Direct single molecule measurement of TCR triggering by agonist pMHC in living

823 primary T cells. Elife 2.

824 Okazawa, H., Motegi, S. -i., Ohyama, N., Ohnishi, H., Tomizawa, T., Kaneko, Y.,

825 Oldenborg, P.-A., Ishikawa, O., and Matozaki, T. (2005). Negative Regulation of

826 Phagocytosis in Macrophages by the CD47-SHPS-1 System. J. Immunol. 174, 2004-

8272011.

828 Oldenborg, P.-A., Gresham, H.D., and Lindberg, F.P. (2001). Cd47-Signal Regulatory

829 Protein a (Sirpa) Regulates Fcy and Complement Receptor-Mediated Phagocytosis. J.

830 Exp. Med. 193, 855-862.

831 Oldenborg, P.A., Zheleznyak, A., Fang, Y.F., Lagenaur, C.F., Gresham, H.D., and

832 Lindberg, F.P. (2000). Role of CD47 as a marker of self on red blood cells. Science 288,

$8332051-2054$.

834 Panni, R.Z., Herndon, J.M., Zuo, C., Hegde, S., Hogg, G.D., Knolhoff, B.L., Breden,

835 M.A., Li, X., Krisnawan, V.E., Khan, S.Q., et al. (2019). Agonism of CD11b reprograms

836 innate immunity to sensitize pancreatic cancer to immunotherapies. Sci. Transl. Med.

83711 , eaau9240.

838 Poon, I.K.H., Lucas, C.D., Rossi, A.G., and Ravichandran, K.S. (2014). Apoptotic cell

839 clearance: basic biology and therapeutic potential. Nat. Rev. Immunol. 14, 166-180.

840 Schmid, E.M., Bakalar, M.H., Choudhuri, K., Weichsel, J., Ann, H.S., Geissler, P.L.,

841 Dustin, M.L., and Fletcher, D.A. (2016). Size-dependent protein segregation at

842 membrane interfaces. Nat. Phys. 12, 704-711.

843 Schmid, M.C., Khan, S.Q., Kaneda, M.M., Pathria, P., Shepard, R., Louis, T.L., Anand,

844 S., Woo, G., Leem, C., Faridi, M.H., et al. (2018). Integrin CD11b activation drives anti-

845 tumor innate immunity. Nat. Commun. 9, 5379.

846 Seiffert, M., Cant, C., Chen, Z., Rappold, I., Brugger, W., Kanz, L., Brown, E.J., Ullrich,

847 A., and Bühring, H.J. (1999). Human signal-regulatory protein is expressed on normal,

848 but not on subsets of leukemic myeloid cells and mediates cellular adhesion involving

849 its counterreceptor CD47. Blood 94, 3633-3643. 
850 Spencer, D.M., Wandless, T.J., Schreiber, S.L., and Crabtree, G.R. (1993). Controlling 851 signal transduction with synthetic ligands. Science 262, 1019-1024.

852 Springer, T.A., and Dustin, M.L. (2011). Integrin inside-out signaling and the

853 immunological synapse. Curr. Opin. Cell Biol. 24, 107-115.

854 Subramanian, S., Parthasarathy, R., Sen, S., Boder, E.T., and Discher, D.E. (2006).

855 Species-and cell type-specific interactions between CD47 and human SIRP?. Blood

856 107, 2548-2556.

857 Tamada, M., Sheetz, M.P., and Sawada, Y. (2004). Activation of a Signaling Cascade

858 by Cytoskeleton Stretch. Dev. Cell 7, 709-718.

859 Tsai, R.K., and Discher, D.E. (2008). Inhibition of "self" engulfment through deactivation

860 of myosin-Il at the phagocytic synapse between human cells. J. Cell Biol. 180, 989-

8611003.

862 Tseng, D., Volkmer, J.-P.J.-P., Willingham, S.B., Contreras-Trujillo, H., Fathman, J.W.,

863 Fernhoff, N.B., Seita, J., Inlay, M.A., Weiskopf, K., Miyanishi, M., et al. (2013). Anti-

864 CD47 antibody-mediated phagocytosis of cancer by macrophages primes an effective

865 antitumor T-cell response. Proc. Natl. Acad. Sci. 110, 11103-11108.

866 Utsugi, T., Schroit, A.J., Connor, J., Bucana, C.D., and Fidler, I.J. (1991). Elevated

867 expression of phosphatidylserine in the outer membrane leaflet of human tumor cells

868 and recognition by activated human blood monocytes. Cancer Res. 51, 3062-3066.

869 Veillette, A., Thibaudeaut, E., and Latour, S. (1998). High expression of inhibitory

870 receptor SHPS-1 and its association with protein-tyrosine phosphatase SHP-1 in

871 macrophages. J. Biol. Chem. 273, 22719-22728.

872 Weischenfeldt, J., and Porse, B. (2008). Bone Marrow-Derived Macrophages (BMM):

873 Isolation and Applications. CSH Protoc. 2008, pdb.prot5080.

874 Willingham, S.B., Volkmer, J.-P., Gentles, A.J., Sahoo, D., Dalerba, P., Mitra, S.S.,

875 Wang, J., Contreras-Trujillo, H., Martin, R., Cohen, J.D., et al. (2012). The CD47-signal

876 regulatory protein alpha (SIRPa) interaction is a therapeutic target for human solid

877 tumors. Proc. Natl. Acad. Sci. 109, 6662-6667.

878 Wong, H.S., Jaumouillé, V., Freeman, S.A., Doodnauth, S.A., Schlam, D., Canton, J.,

879 Mukovozov, I.M., Saric, A., Grinstein, S., and Robinson, L.A. (2016). Chemokine

880 Signaling Enhances CD36 Responsiveness toward Oxidized Low-Density Lipoproteins 
881 and Accelerates Foam Cell Formation. Cell Rep. 14, 2859-2871.

882 Wu, J., Wu, H., An, J., Ballantyne, C.M., and Cyster, J.G. (2018). Critical role of integrin

883 CD11c in splenic dendritic cell capture of missing-self CD47 cells to induce adaptive

884 immunity. Proc. Natl. Acad. Sci. 201805542.

885 Yi, T., Li, J., Chen, H., Hu, Y., Lowell, C.A., and Cyster Correspondence, J.G. (2015).

886 Splenic Dendritic Cells Survey Red Blood Cells for Missing Self-CD47 to Trigger

887 Adaptive Immune Responses. Immunity 43, 764-775.

888 Yu, D.H., Qu, C.K., Henegariu, O., Lu, X., and Feng, G.S. (1998). Protein-tyrosine

889 phosphatase Shp-2 regulates cell spreading, migration, and focal adhesion. J. Biol.

890 Chem. 273, 21125-21131. 
bioRxiv preprint doi: https://doi.org/10.1101/752311; this version posted August 30, 2019. The copyright holder for this preprint (which was not certified by peer review) is the author/funder, who has granted bioRxiv a license to display the preprint in perpetuity. It is made available under

Figure 1: CD47-SIRPA supresses IgG and PS dependent engulfment

A

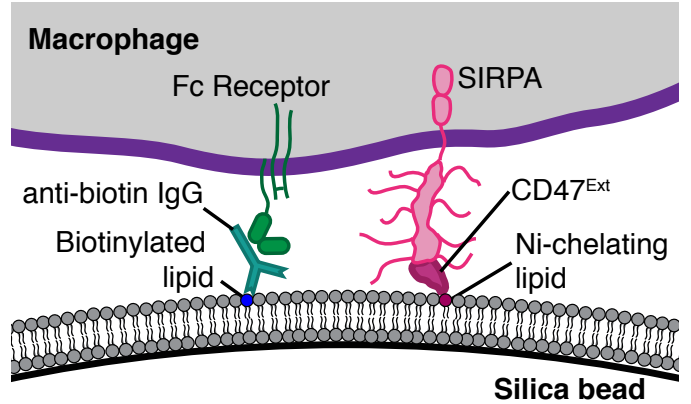

B

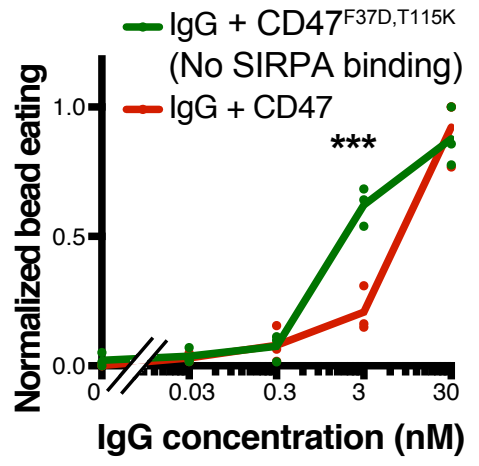

C

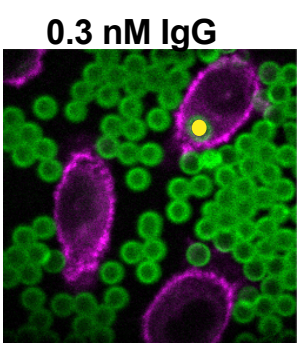

$3 \mathrm{nM} \operatorname{lgG}$
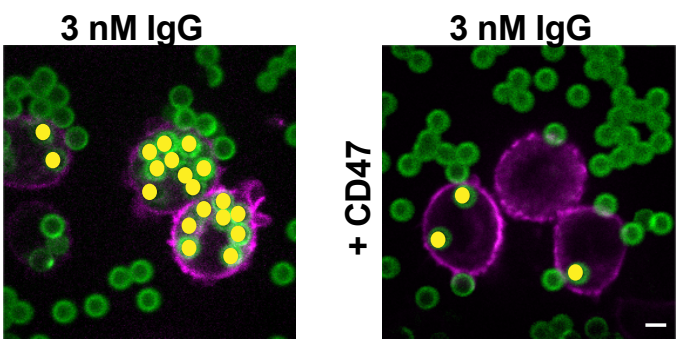

o Internalized

bead

Supported

Lipid Bilayer

Macrophage

Cell Membrane

D

3 nM lgG

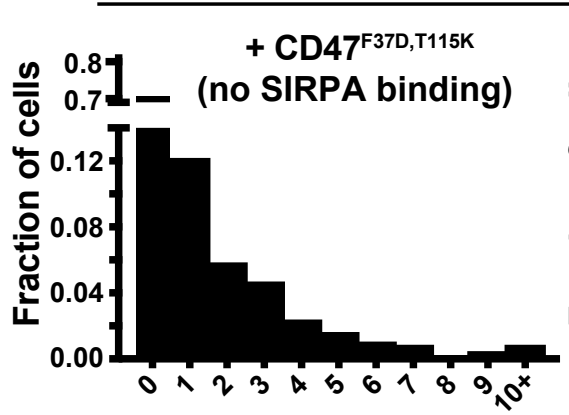

Number of beads eaten

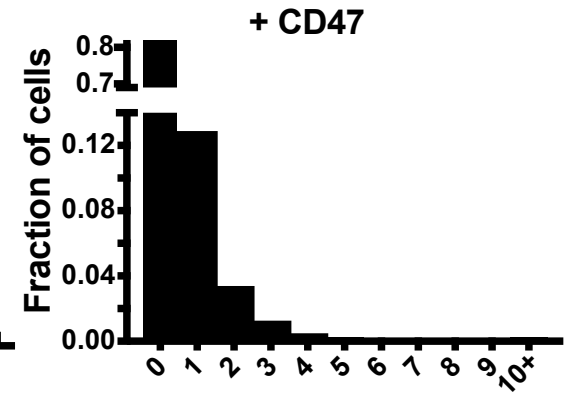

Number of beads eaten
E

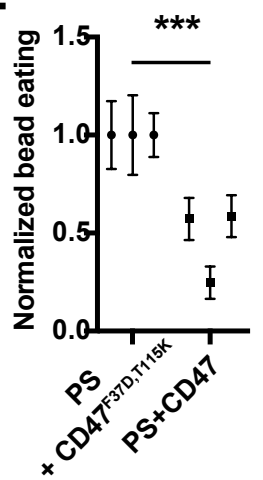




\section{Figure 2: Forcing SIRPA into the macrophage-target synapse supresses engulfment}

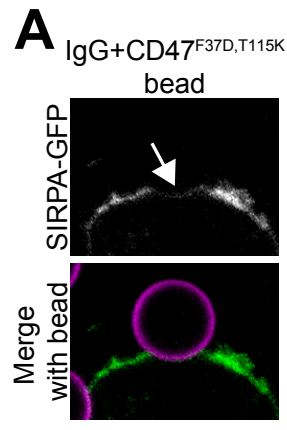

$\lg \mathrm{G}+\mathrm{CD} 47$

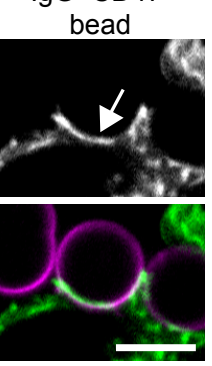

C

SIRPA- FRB ${ }^{\text {ext_SIRPA- FCRI }}{ }^{\text {ext }}$ SIRPA ${ }^{\text {int }}$ GFP
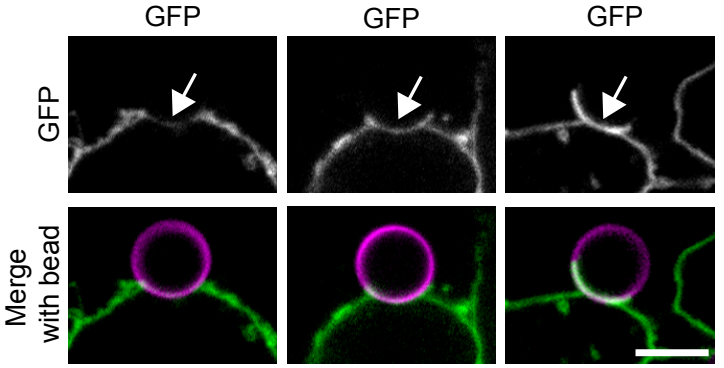

B
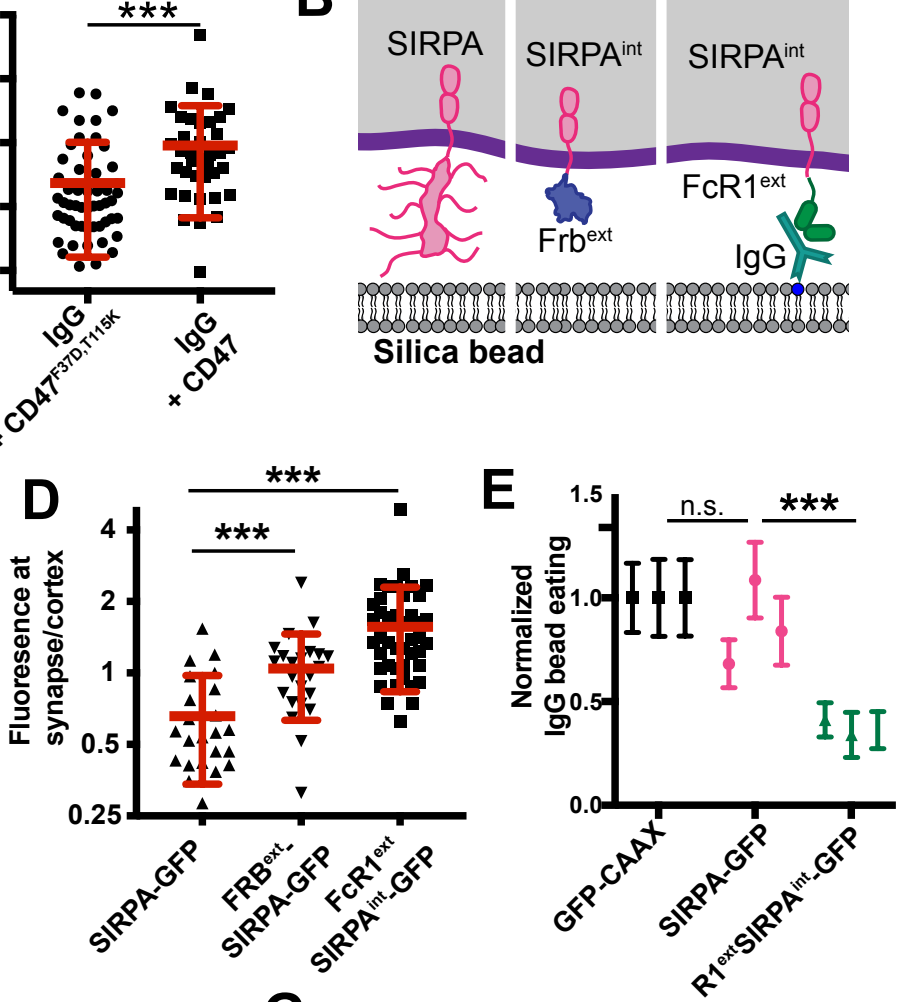

$\mathbf{F}$

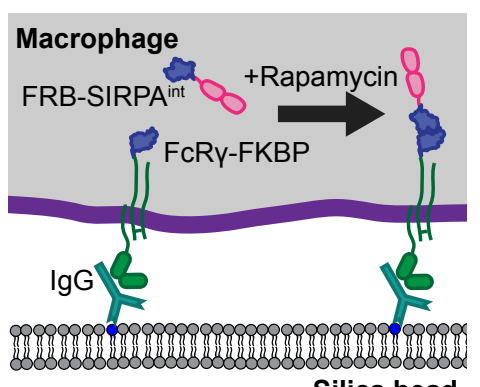

Silica bead

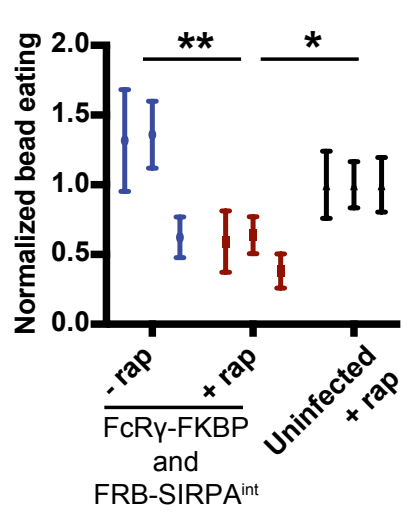

G

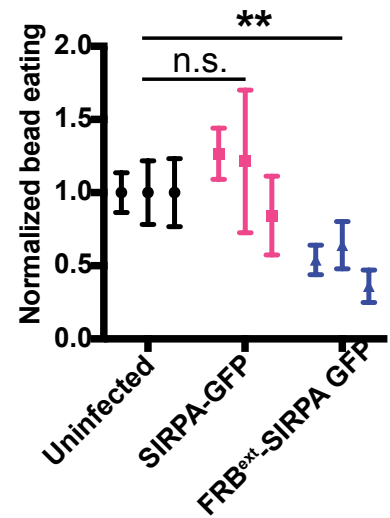




\section{Figure 3: CD47 prevents integrin activation}

A

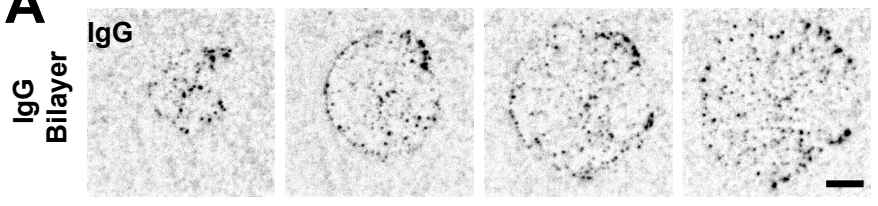

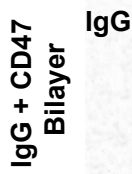

$40 \mathrm{~s}$

$80 \mathrm{~s}$

$120 \mathrm{~s}$

$160 \mathrm{~s}$

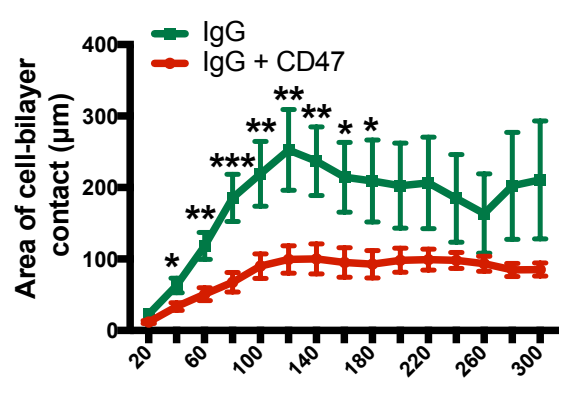

B

IgG
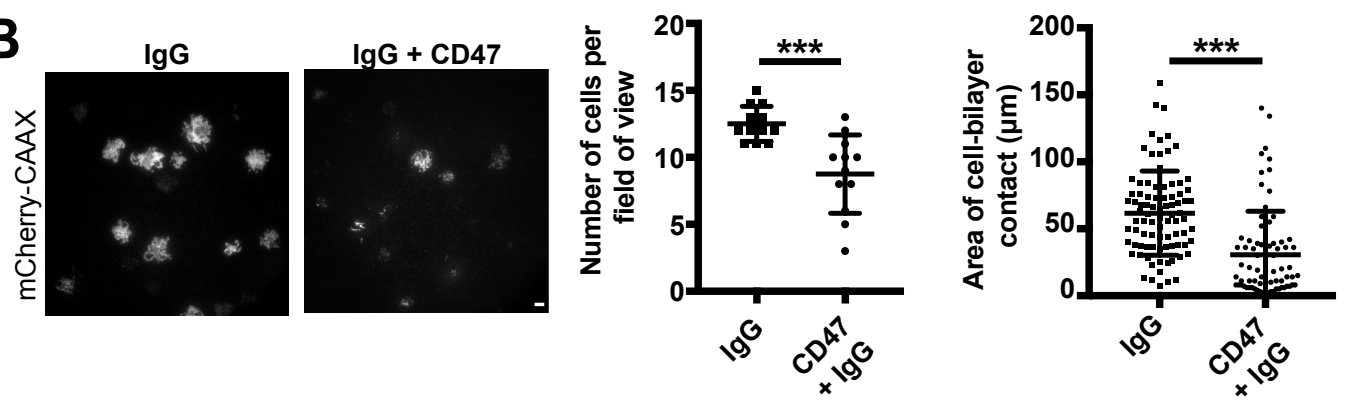

C
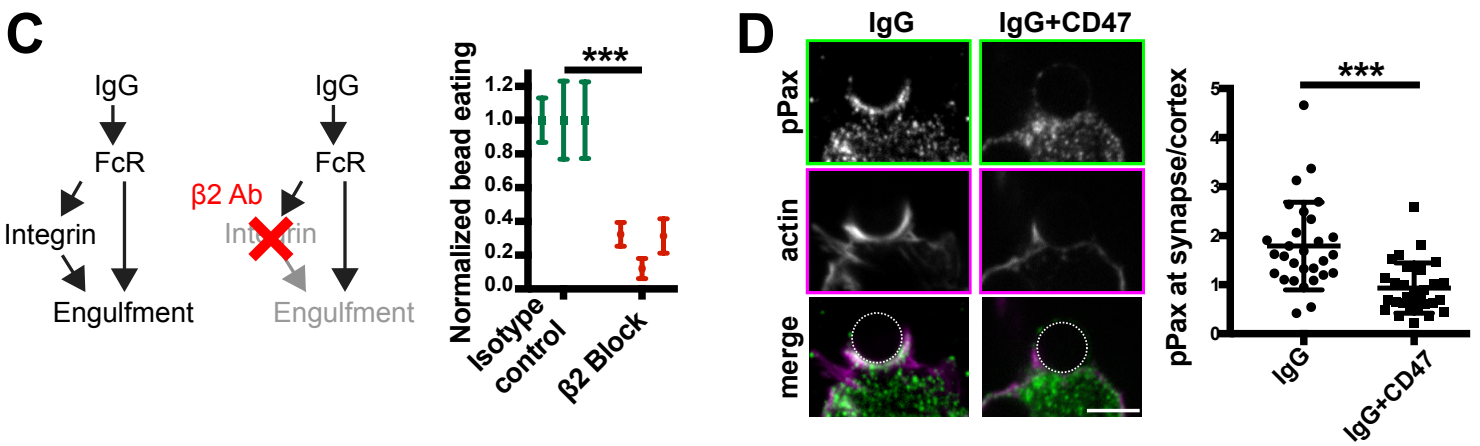


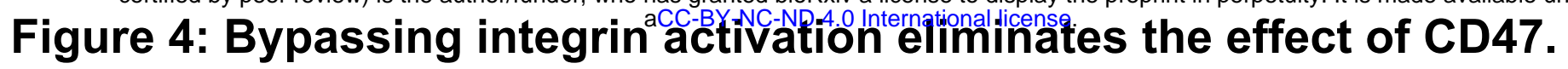

A
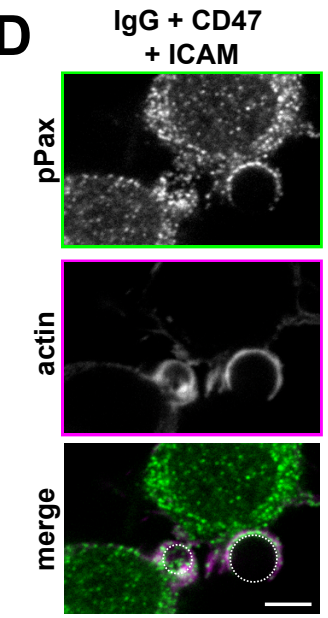

G
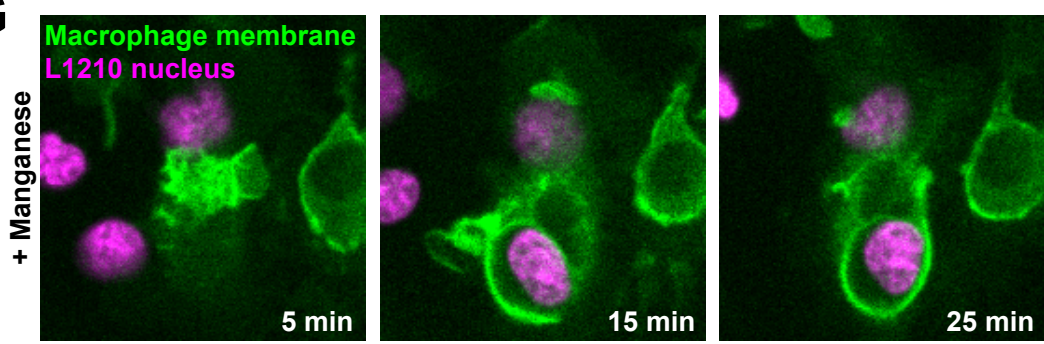

I

\section{Engulf}

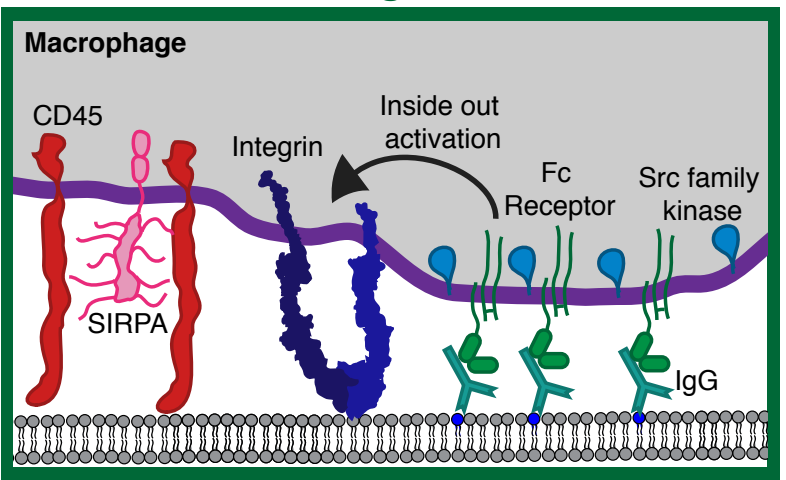

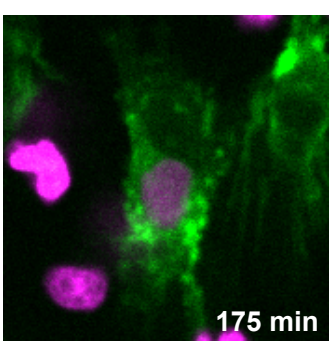

$\mathbf{H}$

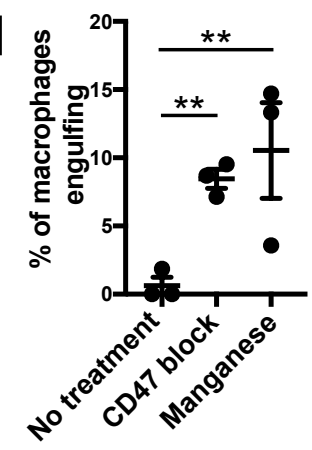

C
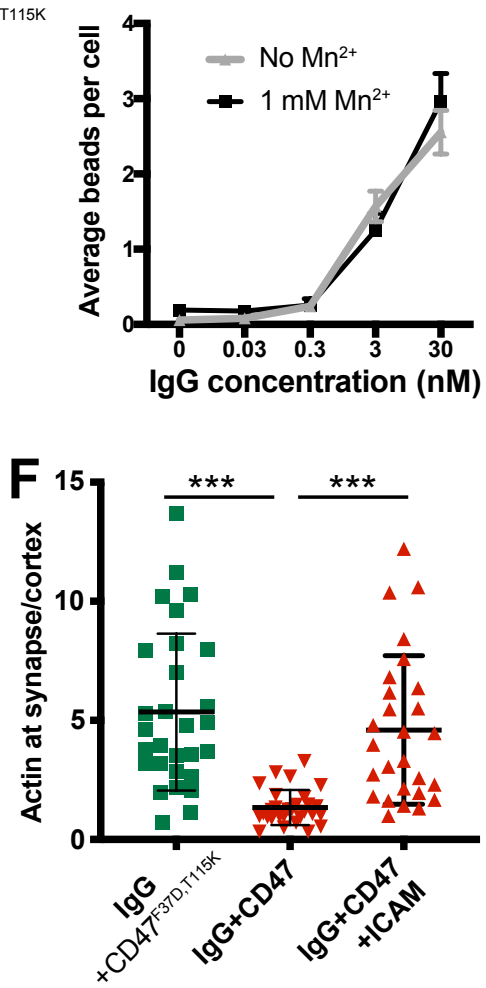

Don't Engulf

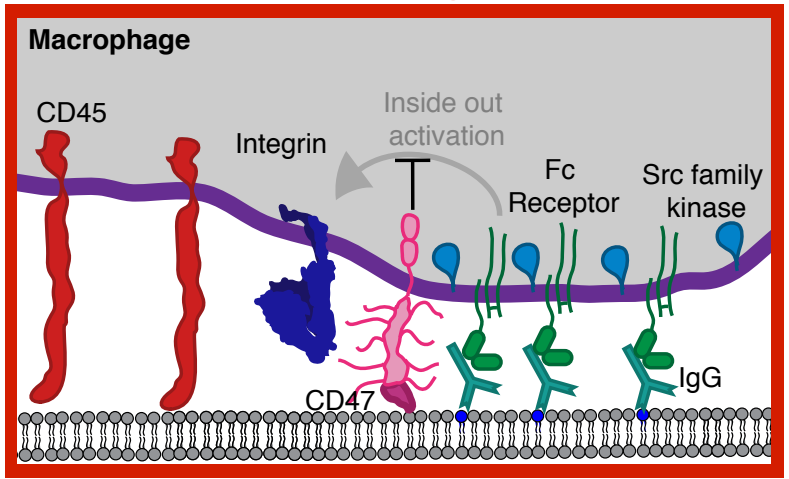

